\title{
Study of drug utilization pattern in gynecology department of tertiary care hospital of Rajasthan, India
}

\author{
Neelam Sharma ${ }^{1}$, Anshul Jhanwar ${ }^{2 *}$ \\ ${ }^{1}$ Department of Obstetrics and Gynecology, Jhalawar Medical College, Jhalawar, Rajasthan, India
}

${ }^{2}$ Department of Pharmacology, Jhalawar Medical College, Jhalawar, Rajasthan, India

Received: 30 May 2018

Accepted: 04 June 2018

*Correspondence:

Dr. Anshul Jhanwar,

E-mail: dranshul123@gmail.com

Copyright: (c) the author(s), publisher and licensee Medip Academy. This is an open-access article distributed under the terms of the Creative Commons Attribution Non-Commercial License, which permits unrestricted non-commercial use, distribution, and reproduction in any medium, provided the original work is properly cited.

\section{ABSTRACT}

Background: With increasing awareness the flow of patients visiting gynecology outpatient department has increased. Drugs used in gynecology are one of the most selling drugs in India, however they are least studied with respect to drug utilization. Thus, present study was undertaken to analyse drug utilization pattern of Gynecology OPD in a tertiary care hospital.

Methods: A retrospective, cross sectional, observational study of prescriptions in Gynecology OPD of Jhalawar medical college, Jhalawar. Data was obtained from medical record database of patients that attended Gynecology OPD from October 2017 to March 2018 over period of six months. Prescription records of patients were screened as per inclusion and exclusion criteria and 300 prescriptions were randomly selected. Patient related, and drug related information was collected on a customized data collection sheet.

Results: The mean age of patients was $20.5 \pm 8.65$ years and common age of presentation was $>18-30$ years. In infective cases, PID (40.6\%) was common, and in non-infective cases, menorrhagia (23.8\%) was common. The average number of drugs per prescription was 5.2. In drug category, minerals (46.4\%) were most commonly prescribed, followed by antimicrobials (27.6\%), and NSAIDs (20.1\%). Polypharmacy was observed in $100 \%$ of the prescriptions.

Conclusions: In the present study all of the drugs prescribed were generic which were from the essential medical list of NLEM and WHO. This study revealed deviation from rational prescribing by the prescribers because average number of drugs per prescription was significantly higher than that recommended by WHO.

Keywords: Drug utilization, Gynecology, Outpatient department

\section{INTRODUCTION}

Drug utilization is defined by the WHO as the "marketing, distribution, prescription, and use of drugs in society, with special emphasis on the resulting medical, social, and economic consequences. ${ }^{1}$ With the increasing awareness, the flow of patients visiting Gynecology OPD has increased. There are only a few comprehensive community-based studies in low income countries that quantify burden of gynecological disease in order to influence health policy with respect to Gynecology.
The assessment of drug utilization is important for clinical, educational and economic purposes. Prescribing patterns need to be evaluated periodically to increase the therapeutic efficacy, decrease adverse effects and provide feedback to prescribers. Inappropriate drug prescribing is a global problem, particularly in developing and transitional countries. Irrational drug use leads to reduction in the quality of drug therapy, wastage of resources, increased treatment cost, increased risk for adverse drug reactions and emergence of drug resistance. ${ }^{2-5}$. 
As per data by All India Origin Chemists and Distributors -Advanced Working, Action and Correction System (AIOCD-AWACS) market research firm, Gynecology drugs are one of the strong selling drugs in pharmaceutical market; they rank as the 8th in all the super groups with $16.4 \%$ growth in the month of February $2012 .{ }^{6}$ However, they are the least studied drugs in terms of drug utilization studies.

There are more effective drugs (medicines) today in the market than ever before. Yet, drugs are frequently not used to their full potential or according to the generally accepted criteria. Patients are better educated, have greater expectations from health care, and frequently use multiple sources of health care. Considering the patient needs on one hand and vast number of drugs available on the other, it is very important to have appropriate prescriptions. All prescribing is not necessarily based on patient needs and all patient needs are not necessarily met with drug therapy. Consequently, there is as much concern about inappropriate and expensive prescribing, as about under-prescribing.

The principal aim of this drug utilization research is to facilitate appropriate use of drugs as per WHO guidelines in patient populations, minimize the adverse event and drug interactions leading to better patient outcome. Considering the flow of the gynecology patients and scarcity of data with respect to drug utilization study (DUS), the present study is planned to examine the patterns of drug prescription in the gynecology outpatient department (OPD).

\section{The objectives of the present study were:}

- To study the drug utilization pattern of drugs used in the gynecology out-patient department of a tertiary care hospital

- Average number of drugs prescribed per prescription and relationship between patient demographics and prescription pattern

- Indications for which various drugs were prescribed and percentage usage of various drugs, various dosage forms of the drugs

- Drugs prescribed by generic name and brand name, drugs prescribed from Indian National List of Essential Medicines (NLEM) 2015, WHO List of
Essential Medicines 2015, fixed drug combinations and poly-pharmacy.

\section{METHODS}

A retrospective, observational, cross sectional study was done by collecting the prescriptions of the patients who attended the Gynecology Outpatient Department of Jhalawar medical college, Jhalawar. The study was conducted after getting approval from the Institutional Ethics Committee.

The 1100 patient's data was screened and analysed as per the inclusion and exclusion criteria during the six months period from October 2017 to March 2018. After screening ,300 prescriptions were selected and analysed. The pro-forma was designed for recording the prescription data like age, diagnosis, month of presentation, drug related information like number of drugs prescribed, drug doses, drug dosage form, route of administration, fixed dose combinations of drugs, drugs prescription by generic or brand names.

\section{Inclusion criteria}

- Data of patients with age $>18$ years after screening having details of parameters under study were included.

\section{Exclusion criteria}

- Data of Gynecology In-door patients during the study duration, emergency patients, Incomplete data.

\section{RESULTS}

Total of 300 prescriptions were analysed. The mean age of presentation was $20.5 \pm 8.65$ years. Among all the prescriptions, $226(75.3 \%)$ were issued to patients from rural area and $74(24.7 \%)$ to patients from urban area. The average no. of drugs per prescription was 5.2.

Out of 300 prescriptions, 180, 96 and 24 were in age group >18-30 years, $>30-50$ years and > 50 years respectively. Out of 300 prescriptions, $128(42.7 \%)$ were infective cases and 172(57.3\%) were non-infective. Distribution of infective diseases among patients visiting Gynecology OPD is given in Table 1 .

Table 1: Distribution of infective diseases according to age groups.

\begin{tabular}{|llllll|}
\hline Infective diseases & Age $>\mathbf{1 8 - 3 0}$ yrs & Age $\mathbf{> 3 0 - 5 0}$ yrs & Age $>\mathbf{5 0}$ yrs & Total & Percentage \\
\hline PID & 32 & 15 & 05 & 52 & 40.6 \\
\hline Vaginal discharge & 27 & 09 & 06 & 42 & 32.8 \\
\hline UTI & 12 & 06 & 03 & 21 & 16.4 \\
\hline Episiotomy wound & 07 & 00 & 00 & 07 & 0.05 \\
\hline Diarrhoea & 04 & 02 & 00 & 06 & 0.046 \\
\hline Total & 82 & 32 & 14 & 128 & 100 \\
\hline
\end{tabular}

PID-Pelvic Inflammatory Disease, UTI- Urinary Tract Infection 
Table 2: Distribution of non- infective diseases according to age groups.

\begin{tabular}{|c|c|c|c|c|c|}
\hline \multirow{2}{*}{ Non-Infective diseases } & \multicolumn{4}{|c|}{ Age wise number of patients (n) } & \multirow[b]{2}{*}{ Percentage } \\
\hline & Age $>18-30$ yrs & Age $>30-50$ yrs & Age $>50$ yrs & Total & \\
\hline Menorrhagia & 25 & 13 & 03 & 41 & 23.8 \\
\hline DUB & 21 & 11 & 00 & 32 & 18.6 \\
\hline Amenorrhoea & 15 & 07 & 00 & 22 & 12.8 \\
\hline Dysmenorrhoea & 19 & 02 & 00 & 21 & 12.2 \\
\hline Irregular menses & 00 & 19 & 00 & 19 & 11.05 \\
\hline PCOD & 18 & 00 & 00 & 18 & 10.5 \\
\hline Fibroid uterus & 00 & 08 & 00 & 08 & 4.7 \\
\hline Prolapse & 00 & 02 & 04 & 06 & 3.5 \\
\hline Adenomyosis & 00 & 02 & 02 & 04 & 2.3 \\
\hline Ca Cervix & 00 & 00 & 01 & 01 & 0.006 \\
\hline Total & 98 & 64 & 10 & 172 & 100 \\
\hline
\end{tabular}

DUB- Dysfunctional uterine bleeding, PCOD- Polycystic ovarian disease, Ca-Carcinoma

Among non-infective cases, menstrual disorders were common, in which menorrhagia was most common followed by DUB and amenorrhoea. Distribution of noninfective diseases among patients visiting gynecology OPD is given in Table 2.

A total of 1560 drugs were prescribed in 300 prescriptions. Among all drugs, tablet forms (66.5) are more commonly prescribed followed by capsule and pessary. Among all drugs, Minerals were most commonly prescribed $(46.4 \%)$. In minerals, iron and folic acid supplements were most common followed by calcium.

Table 3: Distribution of drugs according to various dosage forms.

\begin{tabular}{|lll|} 
Dosage forms & Total drugs(n) & Percent \\
\hline Tablet & 1038 & 66.5 \\
\hline Capsule & 328 & 21 \\
\hline Pessary & 147 & 9.4 \\
\hline Syrup & 47 & 3 \\
\hline Total & 1560 & 100 \\
\hline
\end{tabular}

Table 4: Distribution of drugs according to pharmacological class.

\begin{tabular}{|lll|}
\hline Pharmacological classes & Total drugs(n) & Percent \\
\hline Minerals & 724 & 46.4 \\
\hline Antibiotics & 430 & 27.6 \\
\hline NSAIDs & 313 & 20.1 \\
\hline Hormonal preparations & 53 & 8.3 \\
\hline Miscellaneous & 40 & 2.6 \\
\hline Total & 1560 & 100 \\
\hline
\end{tabular}

The second most common drugs prescribed were antimicrobials, in which, Metronidazole was common followed by Doxycycline, Ciprofloxacin and Cefixime. The third group of drugs commonly prescribed were Nonsteroidal Anti-inflammatory Drugs (NSAIDs), in which Diclofenac was commonly prescribed followed by Paracetamol. Out of $53(8.3 \%)$ hormonal preparations,
Oral Contraceptive Pills (OCP) were commonly prescribed followed by cyclical Progesterone. Out of 1560 drugs prescribed, $100 \%$ drugs were prescribed by generic name, $133(8.5 \%)$ prescribed were fixed dose combination. Polypharmacy (containing $>2$ drugs per prescriptions) was observed in $300(100 \%)$ prescriptions. Distribution of drugs according to various dosage forms and pharmacological classes are given in Table 3 and Table 4 respectively.

\section{DISCUSSION}

In our study mean age of presentation was 20.5 \pm 8.65 years and the most common age group was $>18-30$ years. In studies carried out by Kaur et. al. mean age of women

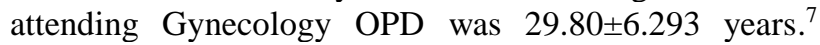
Similarly, Shalini et al reported $70 \%$ patients were between 20-29 years. ${ }^{8}$ This may be due to the fact that in our country, this is the most common age group where females become sexually active. Also, this is the common reproductive age group. Due to lack of awareness, sexually transmitted diseases are common in this age group bringing them to OPD. In present study 226 $(75.3 \%)$ patients were from rural area and $74(24.7 \%)$ patients were from urban area. This indicates that majority of the rural patients depend on the peripheral health services for gynecological diseases. Therefore, these services should be strengthened, and all the essential medicines be made available to reduce morbidity among women from rural areas. Reproductive/Sexual tract infections (RTI/STI) are major cause of gynecological morbidity all over the world. NFHS-3, estimates that $11.1 \%$ of women were reported to have STI in India. ${ }^{9}$ Thapa et al reported that commonest age group of STI is 20-29 years and the most common symptoms are vaginal discharge..$^{10}$

In present study PID is most common infectious disease followed by vaginal discharge and UTI. According to Patel et al, Pelvic Inflammatory Disease (PID) is one of the most serious infections and is a common problem encountered in gynecological clinics in India and 
abroad. ${ }^{11}$ In present study urinary tract infection (UTI) was seen mainly in >18-30 years of age group. As per Gupta et al, more than half of the females with lower urinary tract symptoms were middle aged between 31-55 years of age. ${ }^{12}$

Among menstrual disorders in our study, in >18- 30 years of age group, menorrhagia was common. As per Harlow et al menstrual disturbances are between first and fourth most common reported gynecological complaints in India. ${ }^{13,14}$

Among all the drugs, $46.4 \%$ prescribed were Minerals in which Iron and Folic acid supplements were commonly prescribed. In India 55\% of the females have anemia and is more widespread among both women and children and it has risen almost 5\% points than NFHS-2. ${ }^{15}$ As per Bhatia et al approximately one-third of all women in OPD reported symptoms of anaemia. ${ }^{16}$ In present study diagnosed cases of anemia were less compared to Iron and folic acid supplements prescribed as majority of these were prescribed based on symptoms of anemia. Also, many physicians prescribe these supplements considering the nutritional status and socioeconomic background of Indian women.

The second commonly prescribed group in our study were antimicrobial drugs, in which Metronidazole was common followed by Doxycycline and Ciprofloxacin. In the present study, the encounters with an antibiotic prescription was $27.6 \%$ which is less than the results of Norway (48\%)17 and Iran (61.9\%)18. In a study by Shah et al in indoor patients Ciprofloxacin (60.90\%) was commonly used followed by Ampicillin (54.54\%) and Metronidazole (39.69\%). A number of Indian studies have recorded a high level of use of Metronidazole, Ciprofloxacin, Cefazolin in gynecological department. ${ }^{19}$ As per Sihavong et al, recommended drugs for the treatment of vaginal discharge and lower abdominal pain syndromes include Metronidazole orally or vaginal suppository. ${ }^{20}$ According to WHO, $15-25 \%$ of antibiotics encountered is expectable in the countries where an infectious disease is more prevalent. $^{21}$

The third commonly prescribed drugs in our study were NSAIDs. As per Dhaubhadel et al pain is the most distressing experience of human beings and pelvic pain is one of the most common reasons for gynecology consultation. $^{22}$ The average number of drugs per prescription in present study was 5.2. Since, WHO has recommended that average number of drug per prescription should not be $>2.0$, the results of the study reflect polypharmacy which may lead to adverse drug reactions, increase the risk of drug interactions, dispensing errors, decrease adherence to drug regimens and unnecessary drug expenses. ${ }^{21}$ Due to unawareness of the gynecological diseases there is less follow-up which a contributing factor for the increase in drugs per prescription is. In present study all of the drugs prescribed were generic which were from the essential medical list NLEM (2015) and WHO (2015). ${ }^{23,24}$

\section{CONCLUSION}

Present study focused on understanding drug prescription and trends with respect to Gynecology OPD. This study revealed deviation from rational prescribing by the prescribers because average number of drugs per prescription was significantly higher than that recommended by WHO. It is suggested that periodic evaluation of prescribing practices would help to promote rational practice.

\section{Funding: No funding sources \\ Conflict of interest: None declared}

Ethical approval: The study was approved by the Institutional Ethics Committee

\section{REFERENCES}

1. Truter I. A review of drug utilization studies and methodologies. Jordan J Pharmaceut Sci. 2008;1(2):91-103.

2. Uppal R, Nayak P, Sharma PL. Prescribing trends in internal medicine. Int $\mathrm{J}$ Clin Pharm Ther Toxicol. 1984;22(7):373-6.

3. Krishnaswamy K, Kumar BD, Radhaiah G. A drug survey- precepts and practices. Eur J Clin Pharmacol. 1985;29(3):363-70.

4. Pradhan SC, Shewade DG, Shashindran CH, Bapna JS. Drug utilization studies. National Med J India 1988;1:185-9.

5. Enwere OO, Falade CO. Drug prescribing pattern at the medical outpatient clinic of a tertiary hospital in southwestern Nigeria. Pharmacoepidemiol Drug Saf 2007;16(11):1244-9.

6. Supriya S, Deshmukh Yeshwant A, Mandavi R, Urmila S. Study of drug utilization pattern in the gynecology opd of a tertiary care centre. World $\mathbf{J}$ Pharmacy Pharmaceut Sci. 2014;3(12):916-23.

7. Kaur S, Talwar R, Sabharwal D, Raut DK. Knowledge about transmission dynamics of Sexually transmitted infections. Indian Med Gazette. 2011: 470-5.

8. Shalini S, Murthy NS, Shalini CN, Rajanna MS, Geethamani V. Study of Reproductive tract infections among women attending Urban Health Centres in Banglore City. Indian J Prev Soc Med. 2011;42(3):267-72.

9. Ravi R, Nair SB. Correlates of Sexually Transmitted Infections among Women in Southern India. J Fam Welfare. 2011; 57(1): 45-54.

10. Thappa DM, Kaimal S. Sexually Transmitted Infections in India: Current Status (Except human Immunodeficiency Virus/Aquired Immunodeficiency Syndrome). Indian J Dermatol. 2007;52(2):78-82.

11. Patel SV, Baxi RK, Kotecha PV. A case control study of pelvic inflammatory disease (PID) and its 
association with IUD (Intrauterine device). J Obstet Gynecol India. 2008; 8(4):333-7.

12. Gupta S, Singh O, Shukla S, Mathur RK. Epidemiology, perception and treatment of females presenting with lower urinary tract symptoms at a government hospital in central India. Internet J Surg. 2009;21(1).

13. Harlow SD, Campbell OM. Epidemiology of menstrual disorders in developing countries: a systematic review. Int $\mathbf{J}$ Obstet Gynaecol. 2004;111(1):6-16.

14. Adamson PC, Krupp K, Freeman AH, Klausner JD, Reingold AL, Madhivanan P. Prevalence and correlates of Primary Infertility among young Women in Mysore, India. Indian $\mathbf{J}$ Med Res. 2011:134(4):440-6.

15. NFHS key findings 2005-06. Accessed from http://www.measuredhs.com/pubs/pdf/SR128/ SR128. pdf_on 26 April, 2016.

16. Bhatia JC, Cleland J. Self-reported symptoms of gynecological morbidity and their treatment in south India. Studies Fam Plann. 1995:203-16.

17. Sharif SI, Al-Shaqra M, Hajjar H, Shamout A, Wess L. Patterns of drug prescribing in a hospital in Dubai, United Arab Emirates. Libyan J Med. 2008;3(1):102.

18. Moghadamnia AA, Mirbolooki MR, Aghili MB. General practitioner prescribing patterns in Babol city, Islamic Republic of Iran. East Mediterr Health J. 2002;8:550-5

19. Shah BK, Shah VN. Antimicrobial use by the department of obstetrics and gynecology of a tertiary care hospital: Analysis for rationality and other aspects. J Obstet Gynecol Ind. 2004;54(4):387-92.

20. Sihavong A, Phouthavane T, Lundborg CS, Sayabounthavong K, Syhakhang L, WahlstrÖm R. Reproductive tract infections among women attending a gynecology outpatient department in Vientiane, Lao PDR. Sexually Transmitted Dis. 2007;34(10):791-5.

21. World Health Organization (WHO). International Network for Rational Use of Drugs and World Health Organization. How to investigate drug use in health facilities: Selected drug use indicators 1993. EDM Research Series No. 7 (WHO/DAP/93.1).

22. Dhaubhadel P, Vaidya A, Chaudhary P. Early detection of precursors of cervical cancer with cervical cytology and visual inspection of cervix with acetic acid. J Nepal Med Assoc. 2008; 47(170):71-76.

23. National List of Essential Medicines 2015. Accessed from http://cdsco.nic.in /WriteReadData /NLEM2015/NLEM,\%202015.pdf on 27 April, 2016

24. WHO List of Essential Medicines 2015. Available at http://www.who.int/medicines/ publications/essentialmedicines/EML2015_8-May15.pdf Accessed on 27 April, 2016.

Cite this article as: Sharma N, Jhanwar A. Study of drug utilization pattern in gynecology department of tertiary care hospital of Rajasthan, India. Int J Reprod Contracept Obstet Gynecol 2018;7:2650-4. 